\title{
Da Psicologia à Questáo da "Morte do Homem" em Michel FoucaulT ${ }^{1}$
}

\author{
Marcio Luiz Miotto ${ }^{2}$
}

RESUMO: O presente artigo pretende problematizar, preliminarmente, o "problema antropológico" segundo a arqueologia de Michel Foucault. Partindo de teses populares da Psicologia, em particular, e das ciências humanas, em geral, sobre o "Homem" (seu caráter historicamente privilegiado e sua objetividade intemporal), este texto primeiramente correlaciona essas teses com as problemáticas dos textos foucaultianos dos anos 1950, a Introdução a Sonho e Existência e Maladie Mentale et Personnalité (cada qual encarregado de oferecer um projeto de fundação sobre o Homem), para então mostrar como os textos "arqueológicos" do autor se configuram como respostas iniciais às questôes dos textos de 1954, já começando pelos textos publicados em 1957. Os exemplares privilegiados são História da Loucura e As Palavras e as Coisas: após circunscrever aspectos singulares de cada argumentaçáo, o artigo pretende explorar em que sentido os textos se reúnem sob a questáo mais geral de uma crítica arqueológica à questão antropológica dos "saberes" modernos.

PALAVRAS-CHAVE: Michel Foucault. Ciências humanas. Arqueologia. Modernidade. Filosofia contemporânea. Psicologia.

El tiempo es la sustancia de que estoy hecho. El tiempo es un rio que me arrebata, pero yo soy el río; es un tigre que me destroza, pero yo soy el tigre; es un fuego que me consume, pero yo soy el fuego. El mundo, desgraciadamente, es real; yo, desgraciadamente, soy Borges. (Nueva Refutación del Tiempo)

Sob uma série de temas que percorreram os séculos XIX e XX e se tornaram bastante populares em manuais, a Psicologia, ao contar sua história, multiplicou análises seguindo o modelo da célebre frase de Ebbinghaus (1908 p. 3): “[...] a psicologia tem um longo passado, mesmo que sua história tenha

\footnotetext{
${ }^{1}$ http://dx.doi.org/10.1590/S0101-31732016000200007

Agradecimentos: À FAPESP, por fomentar uma pesquisa de Doutorado derivada de versōes preliminares deste texto.

${ }^{2}$ Prof. Adjunto de Fundamentos Filosóficos da Psicologia (UFF-RPS). Contato: mlmiotto@gmail.com
} 
sido curta”. Sob enunciados tâo frequentes quanto considerados insuspeitos, os livros de psicologia mais difundidos atribuiriam à sua ciência o papel de "[...] uma das mais antigas disciplinas acadêmicas e, ao mesmo tempo, uma das mais novas" (SCHULTZ, D.; SCHULTZ, S., 1969/1981 Cap. 1)3. “Jovem ciência”, ela remontaria, não obstante, aos "primeiros espíritos questionadores". Muitos dos problemas e interrogaçóes dos psicólogos atuais seriam semelhantes aos já refletidos pelos antigos filósofos: memória, aprendizagem, atividade onírica, comportamento anormal... "As mesmas espécies de interrogaçóes feitas atualmente sobre a natureza humana também o eram séculos atrás, o que demonstra uma continuidade vital entre o passado e o presente em termos de seu objeto de estudo". "Continuidade" de problemática, cujo ponto de ruptura separaria a psicologia moderna e seus "antecedentes" por uma questáo de, em meados do século XIX, surgirem métodos "finalmente" científicos, livres da "especulação, a intuição e a generalização baseadas" na "limitada experiência" dos filósofos. A transformação ocorreria precisamente no momento em que os psicólogos passaram a utilizar os "bem-sucedidos" métodos das ciências naturais em seus experimentos. Para as mesmas perguntas, formuladas desde a antiguidade, surgiriam então novos caminhos, "enfim" eficazes para a elucidação das respostas. Métodos que náo cessariam de ser modificados. Sob que circunstâncias proliferaria essa diversidade de métodos "inadequados" encontrados em todo o "longo passado" (ainda não considerado "história"), acompanhada de tanta imprecisão e não apreensão correta do homem? Dentre outras variantes, até entâo o homem seria erroneamente "santificado" (por crendices, abstraçôes, preconceitos...), numa sacralidade que lhe renderia um estatuto anteriormente inalcançável pelos métodos científicos; mas, apesar de tantas perspectivas históricas ditas errôneas, permaneceria ainda um mesmo objeto, sempre presente mas difícil de ser atingido: "a complexidade do ser humano".

Examinando como o rés-do-chão da psicologia, em particular, e de diversas ciências humanas, em geral - e, para além delas, todo um estilo de caracterizar a história das ciências ${ }^{4}$ - contextualiza suas disciplinas, dois fatores

\footnotetext{
${ }^{3}$ As citaçóes não referidas desse primeiro parágrafo obedecem à mesma referência, especialmente à XX edição. Isso para mostrar que as ediçóes posteriores à XX não diferem essencialmente no tom.

${ }^{4}$ Denominado por Georges Canguilhem como uma história de "laboratório" ou de "microscópio mental", cujo mote levaria o pesquisador a confundir a história das ciências com uma espécie de história experimental dos objetos das ciências: objetividade que repousa na história, à mercê do aparecimento de instrumentos complexos e de um olhar "verdadeiramente" objetivo. Cf. por ex. Canguilhem (1975) p. 12-13 ou Mengal (1988).
} 
ficam evidentes: (a) trata-se de traçar uma evolução histórica, em termos de contribuiçóes de autores do passado, mas também de insuficiências desses autores (ainda não aptos a uma visão plenamente científica), no caminho de um saber orientado a uma maior objetividade e elaboração; (b) a tese correlata: por sob todas essas insuficiências e contribuições, por sob intuições fragmentárias, "significaçóes errôneas" e preconceitos, repousaria na História um objeto sempre à espreita, à espera de uma depuração para tornar-se enfim liberto de preconceitos e finalmente científico: o Homem - objeto "complexo", ao mesmo tempo acessível e arredio, ser "loquaz e taciturno" - nas palavras de Georges Canguilhem (1975, p. 367), à mercê de métodos apropriados que o capturem.

A argumentação utilizada por Michel Foucault desde os livros de sua "fase arqueológica" coloca em questáo os dois pressupostos acima destacados, essenciais a tais historiadores e constantes na reflexão do século XX, dos psicólogos, em particular, às ciências humanas, em geral. Primeiramente, a arqueologia foucaultiana não trata "[...] de conhecimentos descritos no seu progresso em direçáo a uma objetividade na qual nossa ciência de hoje pudesse enfim se reconhecer" (FOUCAULT, 1966/1992, p. 11); antes de tudo, seria preciso "[...] renunciar ao conforto das verdades terminais", pois o momento atual figuraria mais como ponto de chegada do que juízo regulador da História. E, quanto ao "muito curioso" homem ao qual se reporta a psicologia, em particular, e as ciências humanas, em geral (FOUCAULT, 1965/1999, p. 206), Foucault demonstra as condições de possibilidade de um saber antropológico ${ }^{6}$, pelo menos de dois modos: em História da Loucura, por via de uma "história do Outro" (FOUCAULT, 1966/1992, p. 14), na qual, pelo viés de uma história do louco, acabou se efetuando, "[...] como que por si mesma” (FOUCAULT, 1961/1999, p. 147), “[...] a história daquilo que tornou possível o próprio aparecimento de uma psicologia" (FOUCAULT, 1972/1995, p. 522); já em As Palavras e as Coisas, empreende-se uma "história

\footnotetext{
${ }^{5}$ Em outras palavras, já a partir de seu primeiro grande livro, História da Loucura, até As Palavras e as Coisas, para mencionar, grosso modo, as posiçōes metodológicas e temáticas adquiridas por Foucault em seus escritos dos anos 60 (caso náo se considerem escritos como La Recherche Scientifique et la Psychologie ou A Psicologia de 1850 a 1950). Os problemas de demarcação da obra de Michel Foucault permanecem ainda em aberto (cf., por exemplo, as posiçóes de Deleuze (1988) e Beatrice Han (2002), que elaboram maneiras diversas de interpretar a relaçáo de Foucault com sua obra e a própria dinâmica interna da obra). Aqui, mencionaremos o "período" arqueológico como o grupamento das posiçôes primeiras de Foucault (grosso modo entre História da Loucura e A Ordem do Discurso) frente aos problemas enunciados por ele mesmo, desde os escritos publicados nos anos 50 , a respeito do estatuto da psicologia, das ciências humanas e da subjetividade moderna.

6 “[...] daí o perigo do 'psicologismo', ou do 'sociologismo' - do que se poderia chamar, numa palavra, “antropologismo”” (FOUCAULT, 1966/1992, p. 365).
} 
do Mesmo", privilegiando uma "análise intradiscursiva" - não uma história da diferença, mas de como cada configuração do saber dispóe "[...] relaçóes de similaridade ou de equivalência que fundam e justificam as palavras, as classificaçôes, as trocas [...]" (1966/1992, p. 13-14). Dois conjuntos argumentativos reportados diretamente às condiçóes de possibilidade dos "saberes" sobre o homem.

Pode-se encarar os problemas da "evolução histórica" e do "homem" analisando a arqueologia foucaultiana por um viés metodológico ${ }^{7}$; mas as duas questôes também podem ser encaradas no teor mesmo dos livros, com base em cada trajetória argumentativa (por exemplo, dessas histórias do Mesmo e do Outro), para demonstrar como o "homem" não existiu sempre, sob que condiçôes "passou" a existir e de que modo Foucault apresenta seu "fim". Nesse sentido, ao lado dos debates de inspiração metodológica, a perspectiva "arqueológica" de Michel Foucault seria inteiramente motivada por uma constante análise crítica e "combativa" (a palavra é de Gerard Lebrun, 1995) contra o que esse autor chama de "solo antropológico" do conhecimento contemporâneo, distribuída em diversos níveis argumentativos presentes nos textos publicados nos anos 60 .

Nisso importa notar, de saída, que a própria problemática arqueológica de Michel Foucault parte de um debate correlato ao elencado acima, a respeito da "história" e do "objeto" da psicologia: são interrogaçóes a respeito da fundação apropriada da psicologia e das ciências humanas, desde os projetos iniciais de Foucault, nos anos 50, que conduzirão o autor ao abandono desses projetos fundacionais em direção à "arqueologia". Tal "passagem" - ainda pouco explorada ${ }^{8}$ - pode ser detectada quando verificamos as diferentes démarches dos textos foucaultianos dos anos 50 , as quais culminarão em sua tese sobre a história da loucura. Do Foucault de 1954 - autor de Maladie Mentale et Personnalité e da longa Introdução a Sonho e Existência, de Biswanger ${ }^{9}$-, aos textos de 1957 e à elaboração de História da Loucura (publicada em 1961),

\footnotetext{
${ }^{7}$ Adentraríamos, nesse sentido, em toda problemática do alinhamento da arqueologia em face das histórias das ideias e das ciências, no debate entre a posiçâo foucaultiana e o estruturalismo, e seríamos conduzidos a todo o universo de questóes evocado pelo menos até A Arqueologia do Saber. Cf., por exemplo, Chaves (1988, p. 11), Veyne (1995) e Machado (1981).

${ }^{8}$ No sentido de que a maioria das pesquisas se situam, hoje, no período "final" dos escritos de Foucault. Sobre pesquisas acerca da "passagem", cf., por ex., Macherey (1985), Moutinho (2004), Gros (1997), Chebili (2005) e Miotto (2005, 2011).

${ }^{9}$ Dois textos bem diferentes, cuja relação permanece ainda pouco explorada. A esse respeito, cf., por exemplo, Moutinho (2004) e Miotto (2011).
} 
encontra-se claramente a passagem de uma postura contestatória de certas correntes da psicologia e sugestão de alternativas fundacionistas, à denúncia das ciências humanas e suas querelas, por via de sua constituição histórica, já presente nos textos de 1957.

Em 1954, a postura contestatória e fundante aparece de dois modos diversos e contraditórios: na Introdução a Binswanger, o projeto consiste em criticar as abordagens "naturalistas" em nome de uma fundação fenomenológico-existencial de toda perspectiva sobre o homem. Para além dos diversos resquícios objetivantes, caberia restituir o homem à sua liberdade mais autêntica, propondo uma nova psicoterapia que, grosso modo, emularia os movimentos da imaginação artística. Já em Maladie Mentale et Personnalité a proposta é de uma "antropologia concreta", amparada em certa confluência entre a reflexologia pavloviana e o marxismo soviético dos anos 50, antevendo a superação das psicopatologias (inclusive as de inspiração fenomenológica) e das velhas analogias entre patologia mental e orgânica. Para além das ilusôes de uma metapatologia comum entre as doenças mentais e orgânicas, o pavlovismo marxizante dos psicólogos soviéticos permitiria detectar o "homem real", que porta "de fato" o fundamento psicofísico da antropologia (FOUCAULT, 1954, p. 16). Os dois textos de 1954 oferecem perspectivas antagônicas (de um lado, a fenomenologia existencial e, de outro, um viés apoiado em certo marxismo soviético com inflexôes do naturalismo pavloviano), mas ambas sob o propósito correlato de corrigir as querelas das ciências humanas, por meio de uma fundação antropológica mais privilegiada.

Quanto aos textos publicados em 1957, mais do que refletir sobre um fundamento para as ciências humanas, eles já pretenderiam ultrapassar o debate histórico/epistemológico ${ }^{10}$. Sob tal teor, não haveria mais alternativa de fundação para a psicologia, pois a pergunta correta sobre suas condiçóes e implicaçôes deveria ser feita, doravante, a respeito de sua existência e prática efetivas: dado que a psicologia inteira pode ser ao mesmo tempo "ciência" ou "reflexão filosofante", pois sempre a decisão por "ser ciência ou não" (psicologia "científica" ou "filosófica", "quantitativa" ou "qualitativa", "natural" ou "significativa" etc.) é acompanhada pela exclusão das outras abordagens a serem negadas, mas que, não obstante, continuarão sendo forçosamente "Psicologia"; dado que a psicologia permite, em sua existência concreta e virtualmente acima

${ }^{10}$ La Psychologie de 1950 à 1950 tem um papel controverso nessas questôes. Segundo Denis Huismann (coordenador da ediçáo), Foucault já teria encaminhado o artigo para publicação em 1953. Cf. Huismann (1990) e Miotto (2011). 
de tais escolhas pela cientificidade, uma prática que não se apoia necessariamente na objetividade constituída da ciência (pois suas abordagens pretendem ser de direito aplicáveis em qualquer contexto, antes e independentemente de sua filiação epistemológica); em suma, dado que a psicologia pode ser ou não ciência numa "possibilidade originária de escolha" que possibilitaria optar ou não por um horizonte científico, sem partir necessariamente dele $e^{11}$; então, é em outro lugar, alheio a um debate de saída epistemológico, que o "fundamento" da psicologia deve ser encontrado. A saber, nas "experiências negativas" que o homem faz de si mesmo em determinado jogo histórico - "experiências" doravante justificadas ou revestidas em termos de disfunção, inadaptação e anormalidade:

É curioso constatar que as aplicaçôes da psicologia não são jamais procedentes de exigências positivas [como nas outras ciências, que grosso modo formulam questóes e ultrapassam problemas no seio de interrogaçóes oriundas de conceitos científicos], mas sobretudo de obstáculos sobre o caminho da prática humana. A psicologia da adaptação do homem ao trabalho nasceu das formas de inadaptação que seguiram o desenvolvimento do taylorismo na América e na Europa. Sabe-se como a psicometria e a medida da inteligência escolar são procedentes dos trabalhos de Binet sobre o atraso escolar e a debilidade mental. [...] Sua positividade, a psicologia empresta das experiências negativas que faz de si mesmo. (FOUCAULT 1957/1994, p. 152-153, grifo nosso).

Em outras palavras, o Foucault de 1957 entrevê na psicologia e nas ciências humanas toda uma relação com o negativo, assentada grosso modo em certo leque de relaçôes históricas estabelecidas entre os homens. A distância forjada entre o homem e, por assim dizer, seu "negativo" - figurado em outro homem -, serviria de crivo inicial para o estabelecimento de relaçóes doravante “científicas". Diante disso, em primeiro lugar, tal questão não se resolveria mais por um debate epistemológico, porque, antes de tudo, seria preciso recorrer à história dessa negatividade anterior ao debate científico; e, por decorrência, a questão do negativo torna-se privilegiada para circunscrever as condiçóes pelas quais o homem será, ao mesmo tempo, detectado como "objeto" (ao mesmo tempo normal e anormal, livre e determinado, incondicionado e condicionado, individual e social, social e natural e assim por diante) e sujeito de uma ciência humana em geral. Em face da questão histórica

\footnotetext{
${ }^{11}$ Do mesmo modo como um psicólogo poderia "escolher" uma abordagem científica ou filosófica para sua prática diária, por exemplo.
} 
da negatividade, a psicologia nada mais faria do que revestir com estatuto científico essa distância primeira estabelecida entre o homem e o homem - não assentada num horizonte de interrogações originariamente científicas sobre os limites práticos e conceituais da ciência, mas em demandas de uma prática justificada a fortiori por certa eficácia aparente ou "positividade imediata" (FOUCAULT, 1957/1994, p. 147) ${ }^{12}$. Se, nos textos de 1954, o problema das ciências humanas se resolvia pelo recurso a uma humanidade mais autêntica (no texto sobre Binswanger) ou desalienada (pela reflexáo antropológica de Maladie Mentale et Personnalité), agora o próprio "homem" vira questão: não se tratará mais de buscar uma teoria adequada para suprimir suas contradiçóes, porém, de mostrar como o homem se tornou "objeto" dentro da negatividade que encontra em sua condição. Quanto a esse "como", os textos de 57 apenas assinalam alusivamente: em La Recherche Scientifique et la Psychologie, tratase do que Foucault chama en passant de um "regresso aos infernos", ou ao momento no qual a psicologia, que "esqueceu a negatividade do homem" e exerce sobre ele sua "vocação eternamente infernal", retira sua positividade da questão do negativo (FOUCAULT, 1957/1994, p. 158). E em La Psychologie de 1850 à 1950, trata-se de encarar o fundo das contradiçóes das teorias psicológicas por meio de uma análise eminentemente histórica (FOUCAULT, 1957/1999, p. 139), presumivelmente exterior aos problemas de história das ideias $^{13}$. Não à toa, no fim dos anos 50 , Foucault escrevia a tese sobre a loucura no acervo de raridades em história da medicina de Eric Waller, em Uppsala, verdadeira incursão nos "infernos" das bibliotecas.

\footnotetext{
${ }^{12}$ Esse é um tema importante que aparecerá, por exemplo, em História da Loucura. Dirá Foucault que a disposição que torna possível o aparecimento da loucura como "doença mental" analisável cientificamente (e do homem, como ser objetivável) só ocorre a partir de uma justaposição de duas "experiências" (alheias ao projeto de objetividade científica), que, no classicismo, eram separadas: uma delas, social e moral (internamento); outra, jurídica e médica. Conforme Foucault, a percepção médica apenas "comandará" as experiências da loucura, na modernidade. Todavia, esse "comando" é resultado de uma operação primeira, na qual a experiência médica inicialmente é "chamada" ao internamento por demandas não científicas (uma experiência jurídico-moral da loucura), para, num segundo momento, revestir esse elemento social e moral pela figura do médico como "cientista" e verdadeiro detentor do asilo (cf. adiante, mas especialmente o Cap. 4 e a parte III de História da Loucura).

${ }^{13}$ Exterior aos problemas tradicionais de história das ideias, mas também dos procedimentos de uma "história epistemológica" à la Canguilhem ou Bachelard. Nesse contexto, os dois escritos foucaultianos de 1957, bem como História da Loucura e alguns textos posteriores, são uma espécie de resposta às questốes levantadas por Canguilhem sobre o fundamento da psicologia, em sua célebre conferência de 1956, intitulada Qu'est-ce que la Psychologie? Um trabalho que elucide como Foucault responde a Canguilhem, nesse sentido, ajudará a compreender a própria posiçáo singular que o autor de História da Loucura estabelece, em face de uma história “epistemológica” das ciências, já no período entre 1957-1961.
} 
Nas linhas acima, vê-se o esboço - entre o Foucault que busca uma fundação das ciências humanas e o "arqueólogo" de História da Loucura - do deslocamento de um problema e da perspectiva de como tratá-lo. Os textos de 1957, embora sugiram o abandono de uma análise histórico-epistemológica tradicional, não fornecem uma resposta rigorosa sobre o estatuto do "fundo" das ciências humanas. Foucault "limita-se" a enunciar que todas as querelas dessas ciências repousam em algo mais do que uma deficiência de teoria ou de método. Mas é importante notar, no esboço acima, dois pontos importantes: primeiramente, as posiçôes de Foucault frente às discussôes sobre a fundação das ciências humanas, em geral (e a psicologia, em particular), cedem espaço à pergunta sobre o próprio "Homem". E, em segundo lugar, a "resposta" sobre o Homem se efetivará em algum tipo de procedimento histórico que não se limita à narrativa de sua depuração enquanto objeto ou questão privilegiada, porém, demonstre como foi historicamente possível essa objetividade (e, por conseguinte, o estatuto das querelas modernas). Caso voltemos à questão exposta acima - de que, sob as formas de uma arqueologia do "Mesmo" e do "Outro", Foucault póe em xeque uma série de postulados dados como inquestionados pelas ciências humanas, em geral, e a psicologia, em particular -, vê-se aí um indício primeiro de como a resposta rigorosa sobre a constituição do "Homem" - a partir das questôes enunciadas pelos textos de 1957 - advirá nas diversas argumentaçóes de seus escritos dos anos 60.

Para tanto, vale reiterar inicialmente que a trajetória dos textos foucaultianos, desde História da Loucura até as consideraçóes de As Palavras $e$ as Coisas, não denota uma mesma démarche ${ }^{14}$. Primeiramente, conforme mencionado, pela alusão do autor a uma "história do Mesmo" e do "Outro", dando um enfoque "intradiscursivo", em As Palavras e as Coisas, e analisando, em História da Loucura, as condiçóes pelas quais a ratio ocidental se relaciona com suas formas de alteridade.

Quanto ao enfoque de Foucault em suas arqueologias, em História da Loucura é preciso observar a questâo de certo estatuto da loucura como "estrutura global", principalmente para quem interpreta o livro com base em certo tom de seu primeiro prefácio. Tal problema concerne à incapacidade de as formas que objetivam a loucura atingirem uma "[...] figura total, que finalmente chegaria, por esse caminho, à sua [da loucura] verdade positiva" (FOUCAULT, 1972/1995, p. 28-29; FRAYZE-PEREIRA, 1985). Essas

\footnotetext{
${ }^{14}$ A título de problematização, o presente trabalho se deterá na análise das proximidades e distâncias das argumentaçōes empregadas por Foucault, em História da Loucura e As Palavras e as Coisas.
} 
formas (a psicologia, entre elas) não podem "[...] demonstrar as condiçôes de surgimento" (FOUCAULT, 1962/1984, p. 71) do fato patológico. Pelo menos sob esse contexto de História da Loucura, para atingir tal âmbito "global", seria preciso restituir a loucura "[...] de certo modo à sua linguagem de origem" (FOUCAULT, 1962/1984 p. 84), exemplificada pela questão denominada, então, "experiência trágica". Sob uma interpretação bastante difundida, desde o primeiro capítulo História da Loucura evidencia: como certa "linguagem" da loucura renascentista (expressa por Bosch, Brueghel e outros pintores, retomada episodicamente por Shakespeare e Cervantes) denotaria uma alteridade detentora de certo "saber", sob as qualidades da "ameaça fascinante", vinda de "outro mundo", sob formas exteriores e insidiosas que "brotam" do “chão" (FOUCAULT, 1962/1984, p. 88; FOUCAULT 1972/1995, p. 14, 22 etc.); como essa linguagem "outra", figurada nos exemplares renascentistas, foi considerada irrisão e ridículo por autores como Erasmo e Sebastian Brant; logo depois, como a dúvida metódica, episódio exemplar da ratio ocidental do séc. XVII, anexa irrecorrivelmente a relação com a verdade à atividade racional e exclui a possibilidade daquele que pensa estar louco, eliminando qualquer possibilidade de "voz" à loucura ${ }^{15}$; e, por fim, como a "libertaçáo" figurada por Pinel e Tuke "coisifica" a loucura e aliena o louco ao querer das prescriçóes médicas e à dinâmica "familiar" do Asilo, não restando voz à loucura senão a de um delírio privado ${ }^{16}$. Sob esse contexto é que se considera História da Loucura a arqueologia de um "silêncio" (FOUCAULT, 1961/1999, p. 141), visto que, antes da transformação da loucura em doença mental e objeto de análise, foi preciso estabelecer um "monólogo" sobre ela - "monólogo" indicativo de que a razáo apenas se relaciona com suas figuras de alteridade, anexando-as sob o discurso racional. "Monólogo" que é ao mesmo tempo condição de possibilidade de uma análise "moderna" das determinações humanas, e condição de impossibilidade de que tal viés analítico dê conta da "estrutura global" do que pretende responder.

Sob tal "monólogo" e impossibilidade moderna, História da Loucura é uma "arqueologia do outro". Ademais, também é démarche peculiar do livro

\footnotetext{
${ }^{15}$ Pela análise da Primeira Meditaçẫo cartesiana e do surgimento do "Grande Confinamento", no segundo capítulo de Folie et Déraison, Foucault descreve a loucura "clássica" essencialmente pelas marcas do erro: erro moral, incapacidade de atingir $a$ verdade, ruptura da relação - mediada por uma razão que adquire facetas morais - com o verdadeiro.

${ }^{16}$ Sobre o louco "coisificado", cf. por ex. Foucault (1972/1995, p. 516); sobre a alienação sob o discurso objetivante da instituiçáo médica: "O momento inicial de todo tratamento será portanto a repressão dessa verdade inadmissível [...] A cura do louco está na razão do outro.” (FOUCAULT, 1972/1995, p. 514).
} 
a ênfase da loucura como "forma primeira" de objetivação do homem. Por exemplo:

\begin{abstract}
A loucura é a forma mais pura, a forma principal e primeira do movimento com o qual a verdade do homem passa para o lado do objeto e se torna acessível a uma percepção científica. $\mathrm{O}$ homem só se torna natureza para si mesmo na medida em que é capaz de loucura. (FOUCAULT, 1972/1995 p. 518).
\end{abstract}

Em outras palavras, foi preciso que, em primeiro lugar, a loucura ocupasse um lugar específico, grosso modo concentrando sobre si diversas práticas e figuras da desrazão clássica - primeiramente confinada e aparentada com os outros "desrazoados" clássicos, então encarada como distinta deles, doravante a única herdeira do internamento e alvo de diversas ordenanças e rotinas institucionais, até a chegada do médico como administrador asilar -, para que, num segundo momento, a figura do médico detectasse, em meio às ordenanças e ao espaço fechado e controlado do asilo, regularidades da conduta do louco que o tornassem objetivável. ${ }^{17}$. Nesse contexto argumentativo, parece ser por meio da loucura como "forma primeira" de objetivaçáo que, posteriormente, os diversos conhecimentos do homem se articularão. Antes da chegada do médico, o louco é observado entre os muros do hospital; suas condutas podem ser anotadas em registros; ele é alvo de rotinas e ordenanças, e os desvios de conduta tornam-se tema para administradores e vigias. Em suma, abre-se um espaço no qual o "homem" poderá ser observado e medido pelo próprio homem, mediante suas figuras de alteridade. Nesse contexto, os textos de 1957 já constatavam a questão dos desdobramentos das figuras humanas e seus negativos: a memória se tornou problema digno de análise psicológica a partir dos desvios da amnésia, a fala por via da afasia etc. Essa ênfase colocada por Foucault à loucura como a "primeira" forma de objetivação do "homem" é importante nesse momento de sua trajetória, porém não aparecerá de forma semelhante em textos posteriores.

Já na argumentação de As Palavras e as Coisas, o nascimento do "homem" como problema privilegiado da modernidade se tematiza com o surgimento das ciências empíricas modernas (especialmente as da "vida", do "trabalho" e da "linguagem"), com base em um "abandono" da representação clássica ${ }^{18}$.

\footnotetext{
${ }^{17}$ cf., a esse respeito, a parte III de História da Loucura, por ex.: Foucault (1972/1995, p. 498)

18 "[...] pois o homem [no classicismo] não existia (assim como a vida, a linguagem e o trabalho)". O homem surge quando, "[...] abandonando o espaço da representaçăo, os seres vivos alojaram-se na profundeza específica da vida, as riquezas no surto progressivo das formas da produção, as palavras no
} 
A loucura terá papel importante, como sendo aquela região transgressora do campo do representável onde, "[...] de propósito deliberado" (FOUCAULT, 1966/1992 p. 391), apontarão as contraciências (veremos). A "região" em que a loucura se encontra será também a da "alteridade", lugar que é condição de possibilidade das Ciências Humanas. Mas em As Palavras e as Coisas não se detecta o mesmo privilégio dado pelo primeiro prefácio de História da Loucura à Experiência Trágica, no sentido de uma "[...] linguagem primitiva (ou 'nascente')" (FRAYZE-PEREIRA, 1985, p. 131). Como se verá a seguir, o livro de 1966 implica transformaçóes imanentes aos saberes de determinada época, não restritos à relação entre a razão e suas figuras de alteridade.

Admitindo as diferenças argumentativas dos livros "arqueológicos", brevemente vistas acima (e mencionadas nas arqueologias do "outro" e do "mesmo"), cabe retornar à problemática geral da arqueologia frente aos deslocamentos dos textos dos anos 50. O problema do homem é ponto de confluência. É o que permite Lebrun, por exemplo, analisar a questão da "transgressão da finitude" moderna na Psicologia, utilizando, dentro da problemática antropológica, citaçóes dos diversos textos foucaultianos dos anos 60: "Será que a psicologia apenas cumpre uma tarefa de obliteração e recalcamento? Não apontará, mesmo sem o saber, para a idéia de uma outra "finitude" - que, esta, já não seria considerada dominável?" (LEBRUN, 1985 , p. 14). Para Lebrun, a "arqueologia" foucaultiana não seria meramente um procedimento "asséptico", preocupado apenas com a "metodologia das ciências humanas" ou com "[...] o nascimento de uma disciplina nova que só mereceria críticas sensatas” (LEBRUN 1995, p. 31). Segundo ele, a paixão mobilizadora do arqueólogo seria de um pensamento essencialmente crítico e "molestador", não restrito a querelas interpretativas e metodológicas. Posição não muito distante de Deleuze, quando este menciona a arqueologia como um procedimento "cômico" (DELEUZE, 1992, p. 121, 123, 130, 132) de "rachar" as "palavras" e as "coisas" (DELEUZE, 1988, p. 61 e 62), para além dos "arrependimentos" (DELEUZE, 1988, p. 24, 60 e 66) ou problemas entrevistos por Foucault desde os primeiros escritos. Certamente Foucault escreve L'Archeologie du Savoir motivado por questôes metodológicas, entretanto, elas não se separam dos diversos problemas motivadores de seus livros, por ex. a polêmica com as ciências humanas, as histórias e a filosofia de seu tempo. Já em La Recherche Scientifique et la Psychologie, Foucault

devir da linguagem" (FOUCAULT, 1966/1992, p. 362). Enquanto Foucault utiliza, para o período clássico, termos como "homogeneidade", "ordenação" e "séries" (FOUCAULT, 1966/1992, p. 363), na modernidade, haverá uma "opacidade", uma "profundeza”, uma "espessura” das "coisas" (veremos). 
desconfiava das práticas que se perpetuavam entre a ciência humana e a posição de expertise técnica simplesmente pela constatação de que são práticas. Mais do que as metodologias criticáveis e as "críticas sensatas" das humanidades, importaria a problemática diante da qual proliferaram tantas metodologias.

Quanto à problemática arqueológica sobre o homem, com base nas interrogaçóes da psicologia e dos textos dos anos 50, Foucault privilegia nos escritos dos anos 60 três períodos distintos (porém, não rigidamente delimitados): a Renascença, do século XVI a meados do século XVII; a Idade Clássica, do século XVII até a segunda metade do século XVIII; e, a partir do século XIX, a constituição da modernidade ${ }^{19}$. E, em relação aos saberes tematizados por Foucault em cada momento histórico, cabe sempre traçar suas condiçóes de possibilidade, seu "solo epistemológico", os "a priori" "históricos" ou "concretos", as "configuraçôes" de cada recorte. Admitindo que o estatuto da psicologia e das ciências humanas na arqueologia foucaultiana é tributário do que Foucault chama de "antropológico", restaria então delimitar, preliminarmente, sob que condiçôes o "homem" não "existia" e passou a "existir", e sob que circunstâncias sua "morte" seria "anunciada". Nesse contexto, as primeiras respostas aos textos de 1957 mostrariam que o problema antropológico não representa nem um objeto privilegiado, nem atemporal, ao contrário do que prescrevem diversas tradiçóes.

No período "clássico", o "homem" não "existia". Não havia formas que o objetivassem, tal como, grosso modo, desde o final do século XVIII, porque "[...] toda reflexão sobre o homem é uma reflexão segunda em relação a um pensamento que, ele, é o primeiro e que é, digamos, o pensamento do infinito" (FOUCAULT, 1965/1999, p. 207) ${ }^{20}$. O pensamento clássico, conforme afirmava Deleuze (1988 p. 133), é um pensamento que "[...] não para de se perder no infinito". A questão do infinito implica-se fundamentalmente com o conhecimento humano. $\mathrm{O}$ entendimento (por exemplo), na leitura deleuziana, é limitado em relaçáo a um entendimento infinito, enquanto, em Foucault, o problema do conhecimento é secundário em relação ao problema da verdade: "Tratava-se sempre de responder a questóes tais como esta: dado que a verdade é o que ela é, ou que a matemática ou a física nos ensinaram tal e tal coisa, como acontece de percebermos como percebemos, conhecermos como conhecemos, de nos enganarmos como nos enganamos?" (FOUCAULT,

\footnotetext{
${ }^{19}$ Essas denominações não são também fixas. Em Les Mots et les Choses, Foucault fala, por exemplo, de uma "Era da Semelhança", de período da "Representaçáo" e de uma "Idade do Homem".

${ }^{20}$ Sobre a questão do "infinito” na análise foucaultiana da idade clássica, cf. Miotto, 2013.
} 
1965/1999, p. 207). Deleuze correlaciona a questâo do infinito com uma palavra frequente em Foucault, para caracterizar o conhecimento clássico:

O que define esse solo [clássico], o que constitui esta grande família de enunciados ditos clássicos, funcionalmente, é esta operação de desenvolvimento ao infinito, de formação de continuuns, de desdobramento de quadros: desdobrar, sempre desdobrar - "explicar". O que é Deus, senão a explicação universal, o desdobramento supremo? O desdobramento aparece aqui como um conceito fundamental, o primeiro aspecto de um pensamento operatório que se encarna na formação clássica. Daí a freqüência da palavra "desdobramento" em Foucault. (DELEUZE, 1988, p. 134-135).

O primado do infinito corresponde a afirmar que o saber clássico constitui um perpétuo "desdobramento" de signos. Dois fatores decorrerão disso: em primeiro lugar, a finitude do homem, em relação a algo "infinito" que o ultrapassa, é condição de impossibilidade das análises do homem como objeto ou elemento inserido nas coisas empíricas, tal como se dará na configuração ou epistémê moderna (veremos). Em segundo lugar: se cabe a hipótese de que o entendimento humano é limitado em relação a um entendimento infinito; se cabe ao entendimento "desdobrar", desenvolver continuuns ao infinito; e se "Deus" configura-se como o "desdobramento supremo"; então, mediante essa filiação a um "infinito" mais originário, abrese a possibilidade de uma "enumeração completa", uma "certeza perfeita", um "[...] conhecimento absolutamente certo das identidades e das diferenças" (FOUCAULT, 1966/1992, p. 70).

Se ocorre desse modo, como caracterizar tal "desdobramento"? O conhecimento clássico "[...] se obtém pela comparação de duas ou várias coisas entre si”, escreve Foucault (1966/1992, p. 67), comparação esta que envolve termos simples (medidas aritméticas, intuiçôes claras e distintas, signos produzidos pela comparaçáo taxonômica geradora de gêneros e espécies etc.) e, mediante a comparação entre cada novo termo e os demais, a proliferaçáo indefinida de séries complexas. "Desdobrar" e desenvolver continuuns implica uma ordenaçâo dos signos, onde, pela comparaçáo, pelo discernimento, "[...] se estabelecem séries onde o primeiro termo é uma natureza da qual se pode ter a intuição independentemente de qualquer outra; e onde os outros termos são estabelecidos segundo diferenças crescentes" (FOUCAULT, 1966/1992, p. 68). "Desdobrar" e "explicar" correspondem a "ordenar". Foucault explora a possibilidade clássica de uma "Ciência Geral da Ordem", na qual, em termos 
gerais, as naturezas simples seriam analisadas pela Máthêsis (com unidades de convenção ou empréstimo, como os signos algébricos, funcionando como termos básicos de comparações para outros termos, permitindo séries comparativas), cabendo à Taxinomia a análise das representaçóes complexas (consistindo numa classificação geral das espécies entre si, para extrair entre elas seus mais diversos caracteres). Uma é correlata da outra. A ordenação, como desdobramento, acarreta que se encontre, para além das semelhanças aparentes e náo refletidas, das crenças ou das descontinuidades não ordenadas, uma "[...] continuidade escondida (e como que confusa) do ser." (FOUCAULT, 1966/1992, p. 88):

Trata-se de afetar com um signo tudo o que pode nos oferecer nossa representaçáo [...]; esses signos devem valer como caracteres, isto é, articular o conjunto da representação em plagas distintas, separadas umas das outras por traços assinaláveis; autorizam, assim, o estabelecimento de um sistema simultâneo, segundo o qual as representaçóes enunciam sua proximidade e seu afastamento, sua vizinhança e suas distâncias. (FOUCAULT, 1966/1992, p. 88).

Além da relação entre o pensamento clássico com o infinito, de seu modo de ordenar e da possibilidade de se atingir conhecimentos efetivos por meio da caracterização de identidades e diferenças, há outro aspecto do saber clássico enquanto "desdobramento" que Foucault opóe à epistémê moderna: esse saber, enquanto análise, implica uma certa transparência, uma disposição de "duas dimensóes" (DELEUZE, 1988, p. 135), uma certa "simplicidade e evidência" (TERNES, 1995, p. 48) dos signos (permitindo a proliferação de "sistemas simultâneos", conforme a citação acima). A evidenciação de termos simples e a composição de quadros cada vez mais complexos por comparação (na qual a ligação entre cada termo e os demais é claramente representável, em séries cada vez mais abrangentes) atesta essa "transparência", diante da qual o Método cartesiano poderia ser citado como um dos exemplares mais evidentes. Ou, segundo sintetiza Machado (1981, p. 68) a respeito da taxinomia, "[...] o conhecimento classificatório náo se interessa por nada que é invisível, secreto, oculto no corpo; é um conhecimento superficial. O sintoma, a verdade da doença, é um fenômeno aparente, manifesto, evidente". Mais do que estruturas invisíveis, o classicismo visaria a ligação entre termos transparentes e comparaçôes assinaláveis. 
O "solo" clássico traçado em As Palavras e as Coisas corresponde ao recorte histórico da loucura como "desrazão", em História da Loucura. No "Grande Internamento", a loucura não é observada pelos médicos, do mesmo modo que o próprio confinamento não recebe estatuto médico ${ }^{21}$. Se não havia observação da loucura, os conhecimentos analíticos a classificavam sob categorias não provindas da experiência direta e controlada com os loucos. Longe do espaço concreto da desrazão, cabia ao classificador das doenças agir "[...] como os pintores que, quando fazem um retrato, têm o cuidado de marcar até os sinais e as menores coisas naturais que se encontram no rosto da pessoa que estão pintando" (FOUCAULT, 1972/1995, p. 190). Novamente ocorre a transparência da ligação das representaçóes entre si. Contudo, em termos gerais, não era preciso observar concretamente os loucos para conhecer a loucura, do mesmo modo que naturalistas como Buffon não precisaram visitar a Índia para representar racionalmente o caráter dos tigres. Tal como, por comparação, os tigres se distinguiam dos outros felinos ${ }^{22}$, a loucura poderia ser definida por suas proximidades e distanciamentos com as outras doenças, ambas as classificações se comportando similarmente a uma grande taxinomia botânica:

A ordem dos botânicos torna-se a organizadora do mundo patológico em sua totalidade, e as doenças se distribuem segundo uma ordem e um espaço que são os da própria razão. O projeto de um jardim das espécies tanto patológicas quanto botânicas - pertence à sabedoria da previdência divina”. (FOUCAULT, 1972/1995, p. 190-191).

Capítulos como "O louco no jardim das espécies" mostram de que modo as diversas taxinomias dos séculos XVII e XVIII descreviam a loucura: gênero abstrato com traços perfeitamente distintos das outras doenças, mas desvinculado da observação das formas concretas nos "hospitais gerais" (a aproximação "moderna" entre a classificação analítica da loucura e a observação concreta dos loucos internados é um dos pontos principais da parte III do livro). Quanto às terapêuticas, quando ocorriam - pois o desrazoado clássico

${ }^{21}$ Conforme já comentava Machado (1981, p. 67), “[...] a relaçáo de força que se estabelece no internamento atinge o louco e não a loucura. [...] A teoria médica que pretende definir a loucura como doença em nenhum momento se apoia em uma observaçáo dos loucos, como procurará fazer a psiquiatria".

${ }^{22}$ Por ex.: "Veremos [...] que o leão não existia na América, e o puma do Peru é um animal de uma espécie diferente. Veremos igualmente que o tigre e a pantera são encontrados apenas no antigo continente, e que os animais da América meridional que recebem esses nomes são de espécies diferentes. $\mathrm{O}$ verdadeiro tigre, o único que deve conservar esse nome, é um animal terrível, e talvez mais temível que o leão: sua ferocidade não é comparável a nada [...]” (BUFFON, 1856, p. 190-191). 
não era confinado no grand enfermement sob propósitos terapêuticos -, elas visavam (dentre outros fatores) a uma fisiologia não dualista, ao invés das profundidades da alma psicológica moderna. Em A água e a loucura (texto semelhante a passagens do capítulo "Médicos e Doentes"), Foucault demonstra como alguns aparelhos empregados sob propósitos fisiológicos no classicismo (a ducha para esfriar os humores maníacos, a cadeira giratória para mover os humores melancólicos...) passam a ser instrumentos de confissão da interioridade, a partir do século XIX, de modo que Leuret utilizava a ducha como castigo para fazer o louco confessar suas condutas inapropriadas, isto é, "tomar consciência" publicamente de seus sintomas (FOUCAULT, 1963/1999). Em termos gerais ${ }^{23}$, o desrazoado clássico não oferecia problema para uma "cura psicológica", pela inexistência do jogo moderno de uma verdade do homem (mais "autêntica" ou menos "alienada", para empregar termos dos textos foucaultianos de 1954) a que seria necessário reconduzir o louco. Este era apartado da verdade ("insensato", ainda não "alienado"), e não de sua verdade ("moderna”) de ser humano, restituível à "saúde” por uma espécie de retorno a si pelas figuras de uma elaboração civilizada e racional (LEBRUN, 1985, p. 15-16).

O saber clássico, conforme visto, garantia a possibilidade de um conhecimento efetivo do mundo, compreendido como ordem representável e "desdobrável” ao "infinito". Construindo caracteres cujas ligaçôes entre os termos são "transparentes" e assinaláveis dentro da grande ordem racional do universo, e sendo um pensamento finito "que se perde no infinito", tal configuração (segundo Foucault) contraria a hipótese histórica de um homem anacrônico e demonstra a inexistência de um "homem" objetivável. Para que o primado antropológico se instaure, deve haver mudanças frente à configuraçáo clássica.

Sobre essas mudanças, em primeiro lugar, a modernidade antropológica não mais se "perderá no infinito". Ocorre uma reviravolta, na qual não é mais

[...] a partir do infinito ou da verdade que se vai colocar o problema do homem como uma espécie de problema de sombra projetada; a partir de Kant, o infinito não é mais dado, não há senão a finitude, e é neste sentido que a crítica kantiana levava consigo a possibilidade - ou o perigo - de uma antropologia. (FOUCAULT, 1965/1999, p. 207).

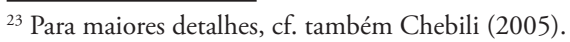


Em outras palavras, uma "[...] finitude constituinte vem substituir o infinito originário", como resumia Deleuze (1988, p. 135). Não mais "secundário" em relação ao infinito, nasce o "homem" como fruto de um certo desequilíbrio: está "[...] no fundamento de todas as positividades, e presente, de uma forma que não se pode sequer dizer privilegiada, no elemento das coisas empíricas" (FOUCAULT, 1966/1992, p. 361). A "modernidade" constitui o "homem" sob certo impasse: oferecido ao mesmo tempo como sujeito $e$ objeto de conhecimento, encontra-se agora "[...] exposto ao acontecimento" (FOUCAULT, 1966/1992, p. 387). Nesse ponto preciso, História da Loucura tematiza o "abandono" da noção de desrazão. Enquanto "desrazoado", "apartado da verdade”, não é possível ao louco clássico uma cura psicológica. Não há "doença mental" ou medicalização nas Instituiçôes de Internamento. A questão de uma “interioridade psicológica doente" se impóe à prática médica apenas na modernidade, tempo no qual, em termos gerais, o louco será alienado na vontade do médico, e as práticas de cura envolverão fatores como a culpabilidade, a confissão, a humilhação e o reconhecimento do louco em face de sua loucura. Novamente o exemplo de Leuret convém: submetese o louco a uma forte ducha, náo para resfriar ou colocar em movimento seus humores, mas como medida culpabilizadora; não se trata de uma medida fisiológica, mas sim de admitir um conteúdo delirante; administra-se a ducha como castigo até que a confirmação do delírio pelo próprio paciente, tornada confissão, seja suficientemente observável e constatável, confrontando o louco com modalidades de comportamentos consideradas mais responsáveis e menos infantis ou degradadas (cf. FOUCAULT, (1963/1999, p. 188), ou também os exemplos de Tuke e Pinel, no cap. "O Nascimento do Asilo".

Pelo louco, o "homem" pode ser conhecido. Constata-se as medidas de sua conduta por meio das medidas institucionais incidentes sobre ele. Notase aqui não mais um conhecimento secundário em relação ao infinito ou à verdade, mas sim que agora o homem pode medir-se "[...] em sua própria desmedida" (FOUCAULT, 1961/1999, p. 142). Mediante um Outro, como desmedida, o homem conhece e reconhece a regra de sua medida. Uma psicologia da memória será possível pela análise da amnésia; uma psicologia da linguagem, definida pela afasia; o normal se conhece pelo anormal, a função, pela disfunção, e assim por diante, segundo já mencionava Foucault em 1957. Conforme frisado, em História da Loucura essa figura da alteridade é importante para compreender o estatuto do "homem", pois nessa regiáo se detectam as condiçóes de possibilidade de uma antropologia. 
Em As Palavras e as Coisas, o "surgimento" do "homem" é correlato ao deslocamento que conduz das ciências gerais clássicas ao aparecimento das ciências da Vida, do Trabalho e da Linguagem. Entre os séculos XVIII e XIX, o homem torna-se um ser vivo entre os demais, para a biologia, um ser falante em meio à profundidade histórica da linguagem, para as filologias, e um ser determinado pelas formas produtivas, para a economia nascente. Grosso modo, ele deixa de ser o agente privilegiado que representa o mundo por termos simples e distintos e passa a ser, ele mesmo, tomado (de forma menos transparente ou privilegiada) no mesmo nível das formas que o objetivam. O "campo do saber perfeitamente homogêneo" (FOUCAULT, 1966/1992, p. 363) da epistémê clássica, constituído por representaçôes ordenadas em continuuns, cede lugar ao abandono das ciências gerais e à fragmentação do campo epistemológico clássico (FOUCAULT, 1966/1992, p. 362-363). O projeto de uma mathesis universalis, na qual todos os conhecimentos poderiam ser planificados ("em duas dimensōes", segundo Deleuze; em "sistema simultâneo", conforme Foucault) e ligados por determinações transparentes, fragmenta-se e se "retrai". Fragmenta-se porque, doravante, a possibilidade de uma ciência geral será frequentemente contradita por ciências que reclamam para si próprias sua autonomia e irredubilidade. E o "retraimento" resultará num novo campo epistemológico, não mais planificado, mas profundo e volumoso, em três dimensóes. Sob o resumo de Deleuze (1988, p. 136), "[...] alguma coisa vem romper as séries, fraturar os continuuns, que não podem mais se desenvolver na superfície. É como o advento de uma nova dimensão, uma profundeza irredutível, que vem ameaçar as ordens da representação infinita”.

Esse conhecimento "volumoso", em "profundidade", "dobrado" sob si próprio (ao invés dos "desdobramentos" clássicos, cf. Deleuze, 1988, p. 135), já dizia respeito, no contexto de História da Loucura, à constituição da interioridade psicológica moderna, ao invés da desrazão clássica. O exemplo de Leuret, acima, revela como os instrumentos terapêuticos infletiram das implicaçôes materiais da fisiologia à criação de mecanismos culpabilizadores, criando pesos e medidas para condutas apropriadas e "sintomas" doentes. A confissão psicológica exige a constituição de uma dimensão "interior", na qual as diferentes condutas se confrontarão com o que deve ser mais ou menos íntimo ou autêntico à natureza humana. Do mesmo modo, a observação dos loucos se reúne com a taxinomia médica, criando as inúmeras querelas em relação ao estatuto dos sintomas que, doravante, oferecem problemas concretos (Organogênese ou psicogênese? Caos psicológico ou determinismo mental? 
Ato responsável ou desproposital? Mecanismo do corpo ou espontaneidade da psiquê? E assim por diante).

Em As Palavras e as Coisas, as "dobras" e "profundidades" modernas constituem o próprio nascimento das ciências empíricas. O nascimento da biologia trouxe o ensinamento de que o homem pode conhecer a vida, mas sob o enigma de ele ser também um vivo entre os demais; as ciências da linguagem reconhecem o homem falante, todavia, apenas mediante uma linguagem com história e regras que o ultrapassam; do mesmo modo, o sujeito humano trabalha, mas é atravessado por determinaçóes de uma produção, concreta, histórica e opaca à atividade sintética. As ciências da "vida", "trabalho" e "linguagem" demonstrariam regras autônomas e autóctones, opacas à simples comparação planificada "clássica" entre as representaçôes.

Ademais, conforme mencionado, o "campo espistemológico" se "fragmenta". Isso conduz ao argumento de Foucault sobre o "triedro dos saberes” moderno (FOUCAULT, 1966/1992, p. 364). Em termos gerais, os saberes modernos constituiriam uma configuração em três dimensóes (imagine-se a própria figura de um triedro ou um gráfico "XYZ"), na qual cada um dos eixos figuraria determinados conhecimentos: as ciências empíricas (da vida, do trabalho e da linguagem), as analíticas da finitude (as diversas querelas filosofantes) e as ciências "duras", desde o fim do séc. XVIII (física, matemática, química...). Dados os eixos, suas intersecçôes formariam "planos", representados pelas disciplinas que fazem interface entre cada eixo ${ }^{24}$. Finalmente, as coordenadas em volume situadas entre os eixos figurariam a situação das ciências humanas. A configuração em "triedro" mostraria que a existência das ciências humanas é inteiramente animada pelos "empréstimos", feitos por elas, de outros campos de positividade, gerando as eternas querelas das humanidades entre os vieses mais filosofantes, cientificistas, românticos etc. Uma vez dados os "empréstimos" de modelo fundamentais, num segundo momento as ciências humanas disputariam, também com a filosofia e as outras ciências, a batalha pelo fundamento do conhecimento. Resultado? Elas seriam constantemente "perigosas e em perigo" (FOUCAULT, 1966/1992, p. 365) - elas devem a própria existência ao empréstimo de campos de análise cuja positividade reside em outros domínios, mas, uma vez estabelecidas, elas requerem o papel de fundar esses mesmos domínios.

\footnotetext{
${ }^{24}$ Por exemplo, uma fenomenologia da linguagem, enquanto "ontologia regional" entre os eixos da analítica da finitude e das ciências empíricas.
} 
Outro sentido da epistémê moderna enquanto "volume" ou "opacidade" consiste, segundo visto, no apontamento de que os "saberes" modernos não se configuram em função da "representação" em sentido clássico. Todo o "geral" da representação do séc. XVII dará lugar ao "fragmentado" (DELEUZE, 1988, p. 137). As ciências empíricas o mostram: cada uma delas circunscreveu inteligibilidades específicas e, nelas, o homem está "exposto ao acontecimento", tornando-se opaco diante de si próprio. Nessas ciências, os elementos empíricos náo se desdobram frente ao primado de um sistema simultâneo de representaçôes; nelas, os elementos empíricos voltam-se "sobre si próprios" (por assim dizer: as profundidades específicas da "vida", as estruturas linguísticas, os modos históricos dispersos de produção...). Novamente: o homem vive, trabalha e fala, porém, a linguagem que fala tem um modo de funcionamento próprio e independente de uma síntese subjetiva, bem como a sociedade em que "vive" e suas funçôes corporais.

Considerar que as coisas se "envolvem em torno de si próprias", dizer que são opacas à atividade do sujeito, significa afirmar que as ciências empíricas inauguram campos analíticos irredutíveis a uma consciência que lhes doa sentido. A vida, o trabalho e a linguagem apontam para questóes exteriores à síntese subjetiva e - de algum modo cuja polêmica ainda faz parte das querelas contemporâneas - constitutivas dela. O homem deixa de ser "embaixador do verbo divino", agente que "desdobra" por comparação as representaçôes do Ser, para deparar-se com "profundidades" irredutíveis, cujas funçóes e estruturas últimas não domina. Contudo, é precisamente nesse ponto que as "Ciências Humanas" encontram sua especificidade: "Foi o envolvimento do trabalho, da vida e da linguagem em torno deles próprios que prescreveu, do exterior, o aparecimento desse novo domínio" (das Ciências Humanas - FOUCAULT, 1966/1992, p. 357). Se as ciências empíricas fragmentam o campo da representação, as ciências humanas terão o projeto virtual de (por assim dizer) refundá-lo, reduplicando os motes de cada saber que empresta, doravante sob uma nova tematização da noção de representação. Em suma: elas prometem restituir, de fato ou de direito, os privilégios de um sujeito que, não obstante, vive, trabalha e fala. Mediante o indivíduo biológico vivo pode-se, por assim dizer, estudar como objeto a unidade sintética do sujeito que representa sua vida; em face de uma linguagem com estrutura autóctone e irredutível às analíticas ocidentais, diante da anterioridade da linguagem às formas de pensamento, julgase possível dar conta da linguagem em geral estudando seu desenvolvimento em qualquer homem empírico, e assim por diante. Não se trata de estudar a vida, o trabalho e a linguagem como o fazem as ciências empíricas, mas sim o 
modo pelo qual o homem representa esses elementos. A representação se torna entâo um "[...] fenômeno de ordem empírica” (FOUCAULT, 1966/1992, p. 380): representaçôes são regras contingentes estudáveis em sujeitos empíricos; grosso modo, regras que garantem um conhecimento científico e a possibilidade de uma fundação epistemológica e, ao mesmo tempo, regras que constituem o próprio sujeito epistemológico que as estuda. Em termos bastante gerais, o homem conhece o homem como objeto pelas mesmas regras constituintes do próprio homem enquanto Sujeito; conhecimento do homem que opera sob a promessa de que qualquer novo fenômeno carregará implicitamente as mesmas regras antropológicas que finalmente o elucidarão (derivação nas "reduplicaçôes" modernas: "empírico-transcendental", "recuo-retorno da origem", "cogitoimpensado").

Todavia, se ocorre assim, as ciências humanas, como afirma Foucault, embrenham perpetuamente o sujeito antropológico "[...] no campo da finitude, da relatividade, da perspectiva" (FOUCAULT, 1966/1992, p. 372). Trata-se de um saber inescapável do representável, mas que busca restituir à representação tudo o que dela escapa. Apontando para uma perpétua explicitação do implícito, as humanas se constituem a partir do problema do "inconsciente", avançando sobre ele pela promessa de um contínuo desvelamento:

Vão [as ciências humanas] do que é dado à representação ao que torna possível a representação, mas que é ainda uma representação. [...] [Buscam] passar de uma evidência imediata e náo-controlada a formas menos transparentes, porém mais fundamentais. [...] No horizonte de toda ciência humana, há o projeto de reconduzir a consciência do homem às suas condiçóes reais, de restituí-la aos conteúdos e às formas que a fizeram nascer e que nela se esquivam; é por isso que o problema do inconsciente [...] é um problema que é, afinal, co-extensivo à sua própria existência. (FOUCAULT, 1966/1992, p. 381).

E é por isso que o saber, em tais ciências, configura-se sempre como válido, porém - de um modo cujas querelas também perduram ainda polêmico dentro de suas pretensóes à universalidade. Em suma: saber cujo flerte com a relatividade faz corpo com o estatuto da finitude moderna, em contraste com os privilégios clássicos:

[...] o momento da finitude é dissolvido no jogo de uma relatividade à qual não é possível escapar e que vale, ela mesma, como um absoluto. Ser finito seria, muito simplesmente, ser tomado pelas leis de uma perspectiva 
que, ao mesmo tempo, permite uma certa apreensão [...] e impede que esta jamais seja intelecção universal e definitiva. (FOUCAULT, 1966/1992, p. 389-390, 398).

Situando-se sempre no campo do representável, o saber do homem segue perpetuamente em direção às "regiôes inconscientes" do próprio saber sobre o homem que, não obstante, oferecerão de algum modo o apaziguamento de novas representações antropológicas. Aposta-se que toda determinação "inconsciente" alheia ao sujeito antropológico é algo da ordem do representável e pode, doravante, ser restituída ao sujeito (o elogio de Hegel a Pinel, no parágrafo 408 da Enciclopédia, é exemplo desde História da Loucura). No entanto, esse avanço das humanas sobre tais regióes se dá como que "virando-lhe as costas" (FOUCAULT, 1966/1992, p. 391), precisamente pela promessa de que qualquer atividade que foge ao sujeito empírico pode de fato ou de direito - ser recapturada por regras do próprio sujeito empírico. Mas de onde derivariam tais pretensóes e promessas de um novo privilégio? Se o Homem é um sujeito cognoscente, mas conhece o homem em geral mediante o homem-objeto que é o mesmo homem cognoscente (só que agora, "exposto ao acontecimento" que se deve investigar), como restituir esse círculo numa antropologia fundante que finalmente ultrapasse esse movimento?

Em polêmica com as ciências humanas, entram nesse cenário as “contraciências" (os exemplares seriam a psicanálise de Lacan e a etnologia de Lévi-Strauss). Ao contrário de uma explicitação do implícito, elas se direcionariam ao problema do inconsciente "[...] de propósito deliberado" (FOUCAULT, 1966/1992, p. 391), sem "dar-lhe as costas". Para Foucault, isso significaria direcionar-se a uma regiâo fundamental: região onde a representação fica como que em suspenso, "[...] aberta, de certo modo, ao fechamento da finitude” (FOUCAULT, 1966/1992, p. 391). Nela, o homem consciente (figurado no sujeito autônomo) depara com um inconsciente irredutível, com significantes linguísticos alheios aos desígnios voluntários, com estruturas culturais determinando o voluntarismo dos atos - em suma, regiáo na qual a "finitude" moderna se "abre". Se os antropologismos retiram seus privilégios da promessa de que, se o homem é objeto, qualquer nova determinação poderia ser restituída de direito à representação do homem-sujeito, as "contraciências", em contrapartida, fundamentalmente polemizariam sobre os limites exteriores da representação. O sujeito antropológico aposta no "fechamento" de uma subjetividade autofundante, que superaria, em seu movimento próprio, o fato 
de ela ser também fundada; quanto às contraciências, elas escancarariam o próprio jogo de onde o homem moderno retiraria, por assim dizer, seu "suposto saber" ou pretensôes autofundantes. Em suma: sob a fórmula foucaultiana, apontando aos limites da representação, as contraciências se direcionariam não a um antropologismo, mas ao que constitui seus limites exteriores, circunscrevendo suas condiçóes de existência: "Elas dissolvem o homem [...] reconduzem-nas [as ciências humanas] a seu suporte epistemológico e não cessam de "desfazer" esse homem que, nas ciências humanas, faz e refaz sua positividade.” (FOUCAULT, 1966/1992, p. 396).

As contraciências expóem "[...] aquilo mesmo que permitiu ao homem ser conhecido" (FOUCAULT, 1966/1992, p. 398). No entanto, conforme pergunta Foucault, contrapor o jogo moderno da subjetividade autofundante, reconduzir o "homem" às suas condiçôes de possibilidade, isso não significaria, tecendo o destino do homem às avessas, também "conduzi-lo a seu fim?" (FOUCAULT, 1966/1992, p. 398). Semelhante ao resultado da argumentação sobre o classicismo, as contraciências não conduzem o "homem" moderno a um estatuto privilegiado e atemporal, mas à crítica de seus limites e projetos. Dados os parâmetros, Foucault lança o juízo do arqueólogo: descrever como o "homem" (e as formas que o objetivam) tornou-se possível, possui uma "data" e é resultado de certas mudanças históricas do "saber"; descrever igualmente que o projeto antropológico de uma subjetividade autofundante foi igualmente criticado por "contraciências" desafiadoras de suas condiçóes e limites; tudo isso não implica dizer que o "homem" não "existiu" sempre e, de algum modo, sob outra disposição histórica, poderia também "deixar" de "existir"?

Coloca-se o problema da "morte do homem". Conforme afirmava Deleuze, o próprio aparecimento dessa figura que é o "homem” já compreende sua morte,

[...] de três maneiras, pelo menos. Por um lado, onde o homem poderia encontrar o fiador de uma identidade, na ausência de Deus? Por outro lado, a própria forma-Homem só se constitui nas dobras da finitude: ela coloca a morte dentro do homem [...] Enfim, as próprias forças da finitude fazem com que o homem só exista através da disseminaçáo dos planos de organização da vida, da dispersão das línguas, da disparidade dos modos de produção [...]. (DELEUZE, 1998, p. 139).

Já em História da Loucura, dava-se à psicologia, em sua própria existência, duas opçóes: 
[...] aprofundar a negatividade do homem ao ponto extremo onde amor e morte pertencem um ao outro indissoluvelmente, bem como o dia e a noite, a repetiçáo atemporal das coisas e a pressa das estaçóes que se sucedem - e acabar por filosofar a marteladas. Ou então exercer-se através das retomadas incessantes, dos ajustamentos do sujeito e do objeto, do interior e do exterior, do vivido e do conhecimento. (FOUCAULT, 1972/1995, p. 522).

Trocando em miúdos: a representação clássica garantia um conhecimento efetivo de signos "transparentes" indefinidamente "desdobráveis", mediante a questão do "infinito". Quanto ao homem moderno, sua finitude é autofundante: ele retira suas garantias a partir do movimento de uma alteridade que confere seus privilégios, mas ao mesmo tempo, alteridade que, para constituir o Homem e garantir seu movimento autofundante, permanece irredutível. Nesse contexto, o que fazer, senáo confrontar o Homem com a região de onde retira suas garantias (e terminar "filosofando a marteladas"), ou mantê-lo na eterna recorrência das "retomadas incessantes" e "ajustamentos"? Uma anedota: Thoreau dizia que as grandes civilizaçóes garantiam seu esplendor fiando-se no grande lastro da Natureza; na ausência disso, de onde o homem moderno retiraria o tutano da vida (the marrow of life), senão do que restou da própria gordura?

Apesar de, no último capítulo de História da Loucura, a questão da "morte do homem" não ser tematizada como em As Palavras e as Coisas, há um interessante "desfecho" para a opção de "filosofar a marteladas". Utilizando as metáforas da razão como "luz" (não mais a luz da verdade, como se faz aludir aos clássicos) e da loucura como "a noite", sugere-se a dependência do Homem moderno frente às figuras de alteridade que o tornaram possível: "É apenas na noite da loucura que a luz é possível, luz que desaparece quando se apaga a sombra que ela dissipa." (FOUCAULT, 1972/1995, p. 520, grifo nosso).

A questão da "morte do homem", na argumentação de Foucault, não conduz, portanto, a uma preocupação milenar com um objeto complexo demais para ser atingido. Trata-se, pelo contrário, do aparecimento do "homem" sob certa disposição histórica. Conforme considerado acima de modo preliminar as consequências últimas devem ser desenvolvidas -, o arsenal "arqueológico" segue contra os dois postulados ilustrados no início do texto (da "evolução histórica" e do "homem como objeto complexo"), firmemente enraizados em textos cuja popularidade não é menor do que a adoção desses postulados por 
cientistas humanos, em geral, e psicólogos, em particular. Igualmente, em Foucault, a questão do "homem" e da crítica aos antropologismos acompanha pari passu a própria arqueologia foucaultiana, desde o início, e respondendo a questôes sobre as ciências humanas já enunciadas pelos textos dos anos 50. A tarefa de delinear a autocrítica de Foucault mediante os anos 50 e correlacionar tais textos com toda a futura "crítica do presente" permanece relativamente aberta. Quanto às problemáticas dos anos 60, seu caráter "molesto" (segundo Lebrun) ainda carrega resultados: não havendo de fato, recoberto na História, um "homem" para além de preconceitos e à espera de métodos apropriados que o capturem, as ciências que o objetivam deparam com duas questôes, cujos resultados não foram ainda plenamente avaliados. A primeira questão é predominantemente ética: a das garantias sobre as relaçôes estabelecidas do homem consigo mesmo, sem um padrão a priori que o mensure ou uma "neutralidade" que o capture. A segunda diz respeito ao "prenúncio" de que outras disposiçôes históricas já se anunciariam no horizonte.

MIOTTO, Marcio Luiz. From psychology to the problem of the "death of man" in Michel Foucault. Trans/form/ação, Marília, v. 39, n. 2, p. 119-146, Abr./Jun., 2016.

\begin{abstract}
This article aims to discuss, on a preliminary basis, the "anthropological question" in the context of Michel Foucault's "archeological" texts. The paper starts with some popular assertions and postulates regarding "man" in the human sciences (his privileged character and objectivity), based on historical examples in the history of psychology. Secondly, the article correlates these postulates with Foucauldian texts published in the 1950s (the introduction to Dream and Existence, and Maladie Mentale et Personnalité), each one providing a singular project for an anthropological view. Finally, it is shown how the "archaeological" texts can be read as initial responses to the questions formulated in 1954 and 1957. The analysis concentrates on Madness and Civilization and The Order of Things, exploring the differences of each argument and discussing how each book contemplates the general question of an archaeological criticism of the anthropological problem.
\end{abstract}

KEYWORDS: Michel Foucault, human sciences, archeology, modern thought, contemporary philosophy, psychology. 


\section{REFERÊNCIAS}

BUFFON, Oeuvres complètes de Buffon, avec des extraits de Daubenton. Paris: Adolphe Delahays, 1856. Tome VII.

CANGUILHEM, G. Études d'histoire et de philosophie des sciences. Paris: Vrin, 1975.

CHAVES, E. Foucault e a psicanálise. Rio de Janeiro: Forense-Universitária, 1988.

CHEBILI, S. Foucault et la psychologie. Paris: Harmattan, 2005.

DELEUZE, G. Foucault. São Paulo: Martins Fontes, 1988.

. Conversaçōes (1972-1990). Rio de Janeiro: Ed. 34, 1992.

EBBINGHAUS, H. Psychology, an elementary text-book. Boston: D. C. Heath \& Co., 1908. FOUCAULT, M. Maladie mentale et personnalité. Paris: PUF, 1954.

FOUCAULT, M. A Psicologia de 1850 a 1950. In: . Problematização do sujeito: psicologia, psiquiatria e psicanálise. Rio de Janeiro: Forense Universitária, 1999. p. 120136. (Ditos e Escritos I). (Texto original de 1957).

. La Recherche scientifique et la psychologie. Paris: Gallimard, 1994. (Ditos e Escritos, I). (Texto original de 1957).

FOUCAULT, M. Prefácio (Folie et Déraison). In: - Problematização do Sujeito: psicologia, psiquiatria e psicanálise. Rio de Janeiro: Forense Universitária, 1999. (Ditos e Escritos, I). (Texto original de 1961).

. História da loucura. São Paulo: Perspectiva, 1995. (Texto original de 1972).

. Doença mental e psicologia. Rio de Janeiro: Tempo Universitário, 1984 (Texto original de 1962).

. A água e a loucura. In:

Problematização do sujeito: psicologia, psiquiatria e psicanálise. Rio de Janeiro: Forense Universitária, 1999. p. 205-209. (Ditos e Escritos, I). (Texto original de 1963).

. Filosofia e psicologia. In: . Problematização do sujeito: psicologia, psiquiatria e psicanálise. Rio de Janeiro: Forense Universitária, 1999. (Ditos e Escritos, I). (Texto original de 1965).

. As Palavras e as coisas. São Paulo: Martins Fontes, 1992. (Texto original de 1966).

FRAYZE-PEREIRA, J. A loucura antes da História. In: RIBEIRO, R. J. (Org.). Recordar Foucault. São Paulo: Brasiliense, 1985. p. 126-135.

GROS, F. Foucault et la folie. Paris: PUF, 1997.

HAN, B. Foucault's critical project: between the transcendental and the historical. Stanford: Stanford University Press, 2002. 
HUISMAN, D. Note sur l'article de Michel Foucault. Revue Internationale de Philosophie, v. 44, n. 173 , p. 177-178, 1990.

LEBRUN, G. Nota sobre la fenomenologia contenida en las palabras y las cosas. In: CANGUILHEM, G. (Org.). Michel Foucault, filósofo. Barcelona: Gedisa, 1995. p. 31-47.

MACHADO, R. Ciência e saber: a trajetória da arqueologia de Michel Foucault. Rio de Janeiro: Graal, 1981.

MACHEREY, P. Nas origens de história da loucura: uma retificação e seus limites. In: RIBEIRO, R. J. (Org.). Recordar Foucault. São Paulo: Brasiliense, 1985. p. 47-71.

MENGAL, P. Pour une histoire de la psychologie. Revue de Synthèse, v. 109, n. 3/4, p. 485-497, 1988.

MIOTTO, M. A crítica à psicologia em história da loucura. 2005. 139f. Dissertação (Mestrado em Filosofia) - Pós-Graduação em Filosofia Moderna e Contemporânea, Universidade Federal do Paraná, Curitiba, 2005.

. O problema antropológico em Michel Foucault. 2011. 236f. Tese (Doutorado em Filosofia) - Pós-Graduação em Filosofia e Metodologia das Ciências, Universidade Federal de São Carlos, São Carlos, 2011.

. Sobre o infinito na idade clássica em Michel Foucault. Ideação, Feira de Santana: UEFS, v. 27, n. 1, p. 157-186, 2013.

MOUTINHO, L. D. Humanismo e anti-humanismo: Foucault e as desventuras da dialética. Natureza Humana, v. 6, n. 2, p. 171-234, 2004.

SCHULTZ, D.; SCHULTZ, S. História da psicologia moderna. São Paulo: Cultrix, 1981. (Texto original de 1969).

TERNES, J. Michel Foucault e o nascimento da modernidade. Tempo Social: Revista de Sociologia da USP, São Paulo, v. 7, n.1-2, p. 45-52, 1995.

VEYNE, P. Como se escreve a história. Brasília: Editora Universidade de Brasília, 1995.

Recebido em 15/12/2015

Aceito em 19/02/2016 
MIOTTO, M. L. 